\title{
Rare case of haemoptysis
}

\author{
Elrasheid Ali Awouda, ${ }^{1}$ Ahmed Anwar Elnori, ${ }^{2}$ AlaEldin Hassan Ahmed ${ }^{1,3}$
}

${ }^{1}$ Department of Respiratory Medicine, Elshaab Teaching Hospital, Khartoum, Sudan ${ }^{2}$ Department of Cardiothoracic Surgery, Ain Shams Faculty of Medicine, Ain Shams, Cairo, Egypt

${ }^{3}$ Faculty of Medicine, Department of Medicine, University of Khartoum, Khartoum, Sudan

\section{Correspondence to} Dr Elrasheid Ali Awouda, awouda71@gmail.com

Accepted 23 December 2016

\section{SUMMARY}

We report a case of a 39-year-old man who presented with coughing up blood for 5 days. On the day of admission, he coughed up about $300 \mathrm{~mL}$ of fresh blood. He mentioned that he has had cough for the past 10 years. On clinical examination, he was afebrile, tachypneic, tahycardic and normotensive. Rest of the physical examination was normal. His oxygen saturation breathing room air was $96 \%$. His full blood count showed haemoglobin $9.3 \mathrm{~g} / \mathrm{dL}$. His chest radiograph was reported as normal. CT chest showed a vascular right paracardiac soft tissue density. On the basis of this, a diagnosis of pulmonary sequestration was considered. CT angiography of the soft tissue density identified multiple sources of systemic arterial blood. Two arteries were arising from the descending aorta and a third artery was coming from the right renal artery. Surgical removal of the sequestrated lobe was performed. The patient has an uneventful postoperative recovery and remained well at follow-up 2 months after surgery.

\section{BACKGROUND}

Haemoptysis is defined as spitting of blood derived from the lungs or the bronchi as a result of pulmonary or bronchial haemorrhage. The causes of haemoptysis are many and its occurrence often indicates sinister thoracic pathology. ${ }^{1}{ }^{2}$ The causes of haemoptysis differ from one part of the world to another and longitudinal studies have shown that its aetiology varies in the same area over time reflecting the changes in the epidemiology of diseases. ${ }^{2}$ In Sudan, haemoptysis is common and probably its commonest cause is active pulmonary tuberculosis. In this report, we present a case with a rare cause of massive haemoptysis caused by pulmonary sequestration emphasising its peculiarity and highlighting important learning points.

\section{CASE PRESENTATION}

A 39-year-old man who is a life-long non-smoker presented to the emergency department of our hospital reporting of coughing up blood for 5 days. His haemoptysis has been increasing and on the day of admission he coughed up about $300 \mathrm{~mL}$ of fresh blood. There was no fever, chest pain, dyspnoea, loss of weight or swelling of the lower limbs. However, he mentioned that he has been frequently coughing for the past 10 years. He had no history of bleeding disorder and was not on anticoagulant therapy.

On clinical examination, he was afebrile, tachypneic with a respiratory rate 28 breaths per minute, tachycardic with a pulse rate of $100 \mathrm{bpm}$ and normotensive with a blood pressure of $130 / 70 \mathrm{~mm} \mathrm{Hg}$. Rest of the physical examination, including chest auscultation, was normal. His oxygen saturation breathing room air was $96 \%$.

His full blood count showed haemoglobin $9.3 \mathrm{~g} /$ $\mathrm{dL}$, WCC $16000 / \mathrm{mm}^{3}$, platelets $343 / \mathrm{mm}^{3}$. His blood picture was normocytic and normochromic. His biochemical profile was normal. Sputum Ziehl-Neelsen stain was negative and his renal profile, ANA and dsDNA were normal.

His chest radiograph was reported as normal (figure 1). CT of the chest with contrast showed a vascular right middle lobe soft tissue density on mediastinal windows (figure 2). Owing to the vascular nature of the right middle lobe soft tissue density, a diagnosis of pulmonary sequestration was suspected and further studies were carried out to identify the source of its blood supply. CT angiography showed right intralobar pulmonary sequestration with multiple sources of systemic arterial blood supply. Figure 3A, B shows two arteries arising from the descending aorta and a third tortuous artery coming from the abdomen. On further imaging, the tortuous artery coming from the abdomen was shown to originate from the right renal artery distal to its origin from the abdominal aorta and heads cranially to cross the diaphragm and shares the blood supply of the soft tissue mass (figure 4).

\section{DIFFERENTIAL DIAGNOSIS}

The differential diagnosis that we initially considered on this patient was lung cancer, pulmonary tuberculosis, bronchiectasis and pulmonary vasculitis. However, chest CT was very likely of

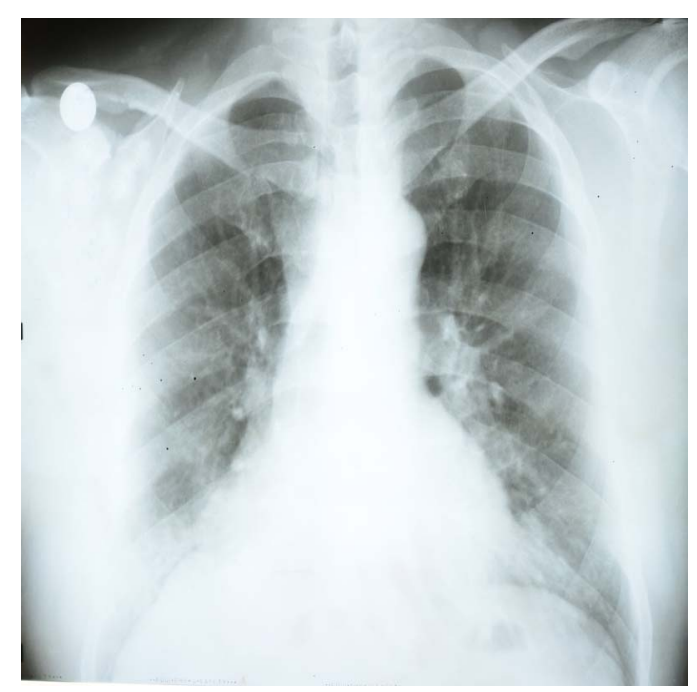

Figure 1 Chest radiograph which was normal. 


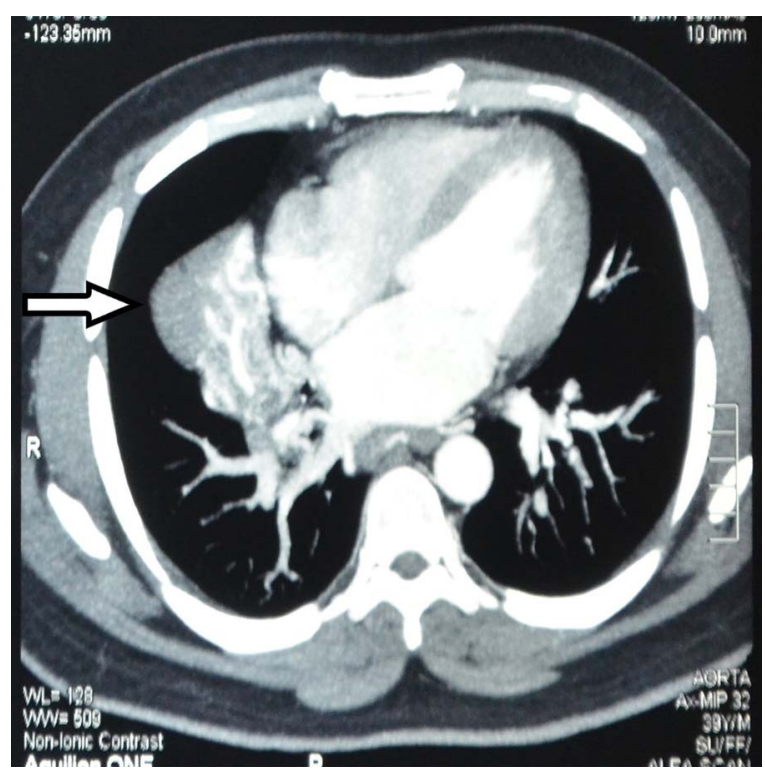

Figure 2 CT of the chest (mediastinal window) showing a vascular right middle lobe mass (arrow).

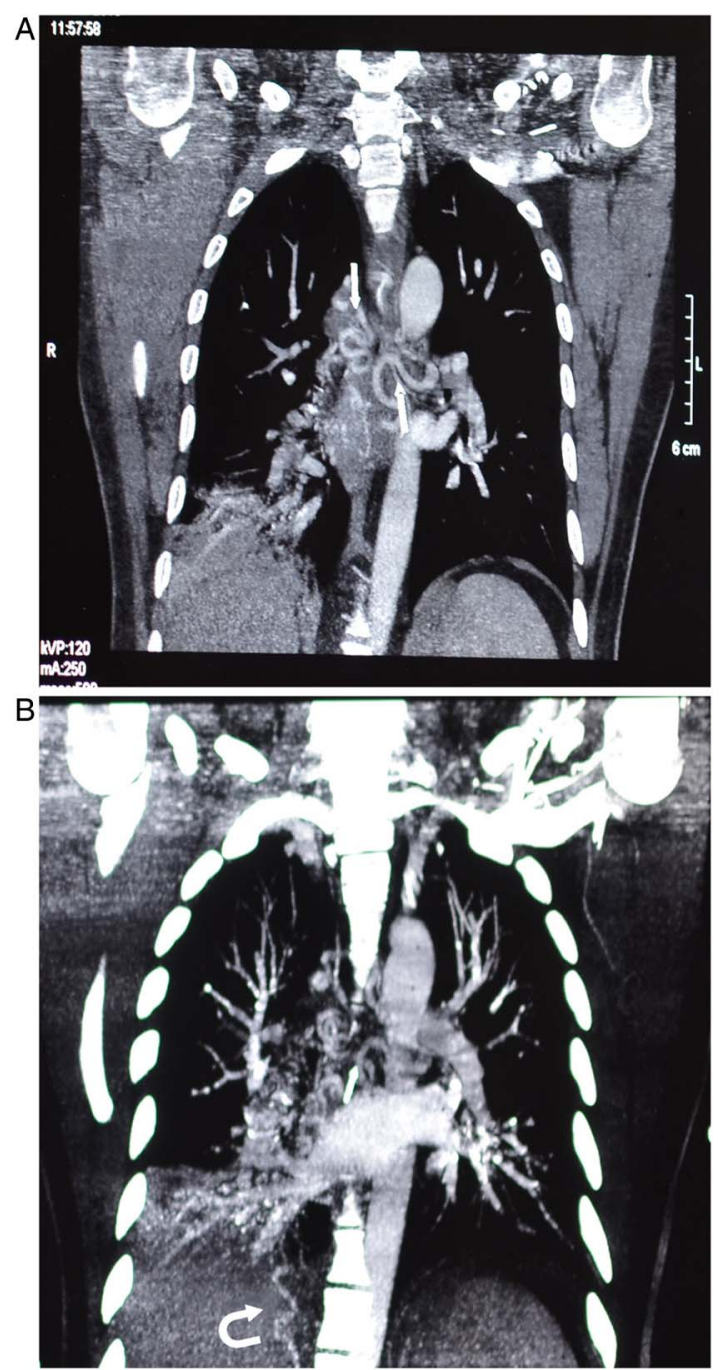

Figure 3 ( $A$ and $B$ ) CT angiography images of the right middle lobe mass showing blood supply from descending aorta (straight arrows $A$ and $B$ ) and tortuous artery coming underneath the diaphragm (curved arrow B).

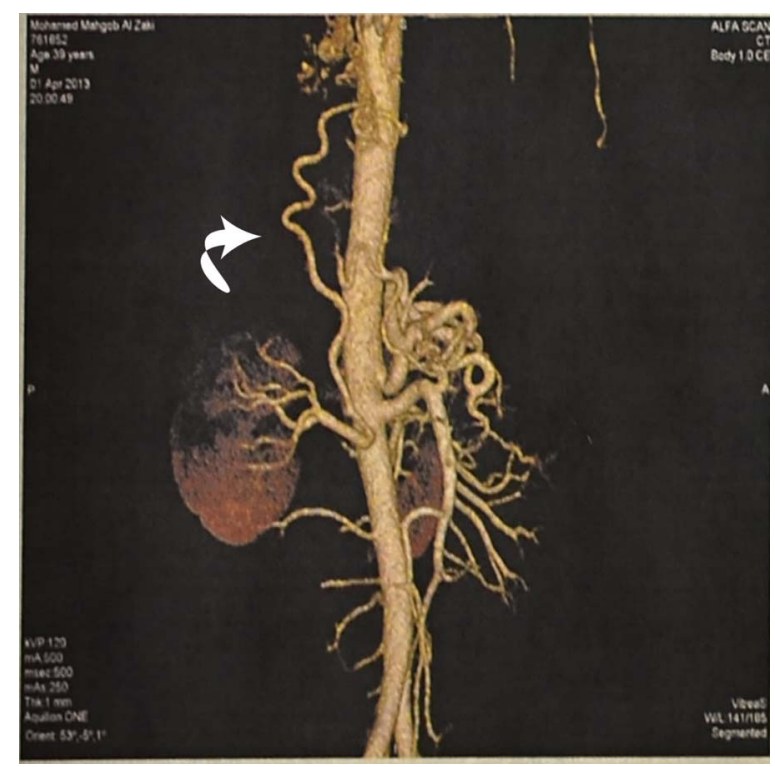

Figure $4 \mathrm{CT}$ angiography image showing blood supply of the right middle lobe mass originating from the right renal artery (curved arrow).

pulmonary sequestration because of the vascular nature of the mass and this was subsequently confirmed on CT angiography.

\section{TREATMENT}

The patient was referred to the thoracic surgeon and surgical removal of the sequestrated lobe was performed.

\section{OUTCOME AND FOLLOW-UP}

The patient had an uneventful postoperative recovery. He was seen for follow-up 2 months after surgery and remained symptoms free.

\section{DISCUSSION}

Pulmonary sequestration is a congenital malformation of unknown aetiology where non-functioning lung tissue lacks communication with the tracheobronchial tree and draws its blood supply from the systemic circulation. ${ }^{3}{ }^{4}$ The condition is rare and accounts for $<1$ in 10 of all congenital pulmonary anomalies. ${ }^{5}$ The supplying aberrant circulation most often arises from the thoracic aorta in $75 \%$ of cases or the abdominal aorta in between $15 \%$ and $20 \%$ of patients. ${ }^{6}$ Blood supply has also been reported to come from smaller thoracic or abdominal arteries and on occasions may come from the coeliac trunk, splenic artery, intercostal or coronary arteries. ${ }^{3} 4{ }^{7}$ Pulmonary sequestration is divided into two types: extralobar sequestration which has its own visceral pleural covering and intralobar sequestration which shares visceral pleura with parent lung. In both forms of sequestration, multiple arterial supplies were found in about the same percentage of cases, about $15 \%$, an observation that is certainly of value to the surgeon's operative approach. $^{6}$

Our case of pulmonary sequestration has many anatomical peculiarities: first, it originates from the right lung whereas most of the cases of sequestration occur in the left lung; ${ }^{6}$ second, the sequestration in our patient involved the middle lobe and in a large series middle lobe sequestration was very rare and occurred in only $0.25 \%$ of cases; ${ }^{6}$ third, it has multiple feeding arteries whereas only $15 \%$ receive blood supply from more than one source. ${ }^{6}$ Finally, the sequestrated lobe in 
our patient draws blood supply from the renal artery and, to the best of our knowledge, this has not been reported previously.

Another peculiar feature of this case is the rather older age at which the diagnosis was reached-39 years. In most cases, initial symptoms occur before the age of 10 years. ${ }^{6}$ However, pulmonary sequestration in adults has been described in refs. [3-7]. In a series of 10 adult patients with a mean age of 35 years, symptoms included cough, haemoptysis, chest pain and back pain. ${ }^{5}$ It is interesting that the diagnosis of sequestration in all 10 patients was made intraoperatively. ${ }^{5}$ The preoperative diagnosis on chest CT was lung mass in six cases, posterior mediastinal mass in two cases, lung cyst in one case and empyema in one case. ${ }^{5}$ Furthermore, two cases of pulmonary sequestration were reported in patients aged 58 and 52 years. ${ }^{4}$ The symptoms in these two cases included sudden onset chest pain, haemoptysis and shortness of breath. ${ }^{4} 7$ The diagnosis was made using CT angiography in one patient; ${ }^{4}$ in the other patient, the diagnosis was initially suspected on coronary angiography and was subsequently apparent on CT of the chest. ${ }^{7}$ Our patient gave a 10-year history of recurrent cough, and this may have been because of recurrent chest infections, but because cough is a rather a common and nonspecific symptom; the diagnosed was not made earlier. What prompted us to investigate this patient and reach a diagnosis

\section{Learning points}

- Diagnosis of lung sequestration requires a high index of suspicion because haemoptysis and chronic cough are common symptoms that are caused by many diseases.

- In a patient presenting with haemoptysis, a normal chest radiograph does not rule out the presence of serious lung pathology and patients should be investigated further by chest CT.

- CT angiography is the radiographic investigation of choice for identifying the source of blood supply of a sequestrated lobe.

- It is crucial to identify all feeding arteries of a sequestrated lobe before surgery. was the occurrence of massive haemoptysis. Minor haemoptysis is common in sequestration and is usually associated with infection. ${ }^{8}$ Massive haemoptysis in sequestration, however, has been described and is thought to result from the anomalous systemic arteries. ${ }^{8} 9$

Pulmonary sequestration has conventionally been treated by surgical removal of the sequestrated lobe of lung. ${ }^{10}$ Embolisation has been reported as a safe alternative to surgery in some patients. ${ }^{10}$ In our patient, surgery was thought to be the best option because of the profuse blood supply that was coming from many arteries. Certainly, accurate preoperative evaluation of the vascular supply of a sequestration is essential for the surgeon's operative approach. ${ }^{7}$

Contributors EAA contributed to conducting the literature search, writing the body of the case report and learning points, and preparing the photos. AHA contributed to reviewing and writing some of learning points. AAE gave feedback of the outcome and follow-up and reviewed the case report.

Competing interests None declared.

Patient consent Obtained.

Provenance and peer review Not commissioned; externally peer reviewed.

\section{REFERENCES}

1 Reechaipichitkul W, Latong S. Etiology and treatment outcomes of massive hemoptysis. Chest 2005;9:8-9.

2 Johnston H, Reisz G. Changing spectrum of hemoptysis: underlying causes in 148 patients undergoing diagnostic flexible fiberoptic bronchoscopy. Arch Intern Med 1989;149:1666-8.

3 Pikwer A, Gyllstedt E, Lillo-Gil R, et al. Pulmonary sequestration: a review of 8 cases treated with lobectomy. Scand J Surg. 2006;95:190-4

4 Reuben Grech, Grima Marius, Warren Scicluna, et al. Bilateral intralobar pulmonary sequestration. Malta Med J 2009;21:30-3.

5 Pekçolaklar A, Çitak N, Metin M, et al. The rare congenital anomaly of pulmonary sequestration experience and review of literature. Indian J Thoracic Cardiovasc Surg 2010;26:251-4.

6 Savic $B$, Birtel $F$, Tholen $W$, et al. Lung sequestration: report of seven cases and review of 540 published cases. Thorax 1979;34:96-101.

7 Bertsch G, Markert T, Hahn D, et al. Intralobar lung sequestration with systemic coronary arterial supply. Eur Radiol 1999;9:1324-6.

8 Rubin EM, Garcia H, Horowitz MD, et al. Fatal massive hemoptysis secondary to intralobar sequestration. Chest 1994;106:954-5.

9 Frazier AA, De Christenson ML, Stocker JT, et al. Intralobar sequestration: radiologic-pathologic correlation. Radiographics 1997;17:725-45.

10 Tokel K, Boyvat F, Varan B. Coil embolization of pulmonary sequestration in two infants. AJR Am J Roentgenol 2000;175:993-5.

Copyright 2017 BMJ Publishing Group. All rights reserved. For permission to reuse any of this content visit

http://group.bmj.com/group/rights-licensing/permissions.

BMJ Case Report Fellows may re-use this article for personal use and teaching without any further permission.

Become a Fellow of BMJ Case Reports today and you can:

- Submit as many cases as you like

- Enjoy fast sympathetic peer review and rapid publication of accepted articles

- Access all the published articles

- Re-use any of the published material for personal use and teaching without further permission

For information on Institutional Fellowships contact consortiasales@bmjgroup.com

Visit casereports.bmj.com for more articles like this and to become a Fellow 